\title{
Evaluation of small airway function and its application in patients with chronic obstructive pulmonary disease (Review)
}

\author{
YAN LI ${ }^{1}$, XIN-YANG LI ${ }^{2}$, LI-RONG YUAN ${ }^{1}$, HAI-LONG WANG ${ }^{2}$ and MIN PANG ${ }^{1}$ \\ ${ }^{1}$ Department of Pulmonary and Critical Care Medicine, The First Hospital, Shanxi Medical University, Taiyuan, \\ Shanxi 030001; ${ }^{2}$ Department of Medical Parasitology, School of Basic Medicine, Basic Medical Science Center, \\ Shanxi Medical University, Jinzhong, Shanxi 030600, P.R. China
}

Received July 20, 2021; Accepted August 26, 2021

DOI: $10.3892 / \mathrm{etm} .2021 .10822$

\begin{abstract}
Chronic obstructive pulmonary disease (COPD) is a chronic airway inflammatory disease characterized by incomplete reversible airflow limitation. The diagnosis of COPD is mainly based on pulmonary function examination. In recent years, it has been indicated that small airway dysfunction occurs in patients with all stages of COPD, even in high-risk smoking groups who have not yet met the diagnostic criteria for COPD. Early recognition of small airway dysfunction and early initiation of small airway targeted therapy have become foci of research. In the present review, the methods of evaluating small airway function were summarized and their merits and shortcomings were discussed. Furthermore, the potential of targeted treatment of small airways in patients with COPD was outlined.
\end{abstract}

\section{Contents}

1. Introduction

2. Evaluation of small airway function

3. Treatment/management of COPD

4. Conclusion

\section{Introduction}

Chronic obstructive pulmonary disease (COPD) is a type of chronic airway inflammatory disease. The clinical symptoms of COPD are chronic cough, expectoration of sputum, wheezing and shortness of breath. COPD is typically marked

Correspondence to: Professor Min Pang, Department of Pulmonary and Critical Care Medicine, The First Hospital, Shanxi Medical University, 85 Jiefang South Road, Taiyuan, Shanxi 030001, P.R. China

E-mail: pangmin2009@126.com

Key words: chronic obstructive pulmonary disease, small airways, dysfunction, diagnosis technique, targeted therapy by high rates of morbidity and mortality, and the lack of early diagnosis imposes a heavy economic and social burden on the world (1). In recent years, it has been indicated that small airway dysfunction occurs in patients with all stages of COPD, even in high-risk smoking groups who have not yet met the diagnostic criteria for COPD (2). There is increasing interest to detect small airway dysfunction and screen patients suspected to have COPD early. There are numerous methods for detecting small airway dysfunction but there is no consensus on the gold standard for diagnosis (Table I). Furthermore, small airway targeted therapy is still in the exploratory stage. Therefore, the aim of the present review was to elaborate on the assessment of small airway function and targeted treatment of small airways in patients with COPD.

The small airways, which are the peripheral airways, whose internal diameter is $<2 \mathrm{~mm}$, are located from the seventh or eighth generation of airways to the respiratory bronchioles. As a consequence of their small lumen diameter, the wall is mostly without cartilage, the total cross-sectional area is large and airflow velocity is slow; thus, small airways are relatively more vulnerable to damage by toxic particles and harmful gases, thus leading to stenosis and occlusion (3). In recent years, as research has progressed, it has been indicated that small airway diseases are widely present in various diseases, particularly COPD. In patients with COPD, peripheral airways, rather than proximal airways, are the predominant site of airflow resistance (4). The small airways of patients with COPD have various lesions due to processes including airway remodelling, mucous plugging and neutrophil and lymphocyte infiltration, and ultimately, the volume of small airways decreases. Furthermore, the degree of inflammation, airway wall thickness and the number of small airways are all correlated with the severity of the disease (5). In addition, small airway dysfunction is closely related to certain patient clusters of COPD who are exposed to smoke and biomass and who have more severe clinical manifestations and frequent exacerbators (6). Therefore, early recognition of small airway dysfunction and early initiation of small airway targeted therapy are of great significance.

\section{Evaluation of small airway function}

Spirometry. Spirometry is the most commonly used method in the assessment of pulmonary ventilation. The indicators of 
forced expiratory flow (FEF)50\%, FEF75\% and FEF25-75\% [also known as maximum midexpiratory flow (MMEF)], are the most frequently used to evaluate the function of small airways. It is now generally accepted that there is small airway dysfunction when two of the above three indicators are below the expected value of $65 \%$ (7). It has been indicated that MMEF may be used to screen patients with suspected early COPD who have clinical symptoms, but whose pulmonary function examination has not yet detected the presence of persistent airflow limitation, suggesting that MMEF may be used as an indicator of small airway dysfunction in early COPD (8). These indicators are easy to obtain, but MMEF relies on forced vital capacity (FVC) measurement, with poor reproducibility and sensitivity. Furthermore, there is a small correlation between MMEF and other indicators, such as gas trapping and small airway inflammation determined by lung biopsies obtained through bronchoscopy. Therefore, the American Thoracic Society does not support its use for determining small airway disease (7). In addition, compared with MMEF, there are numerous other indicators of small airway function with better accuracy and sensitivity. Forced expiratory volume (FEV) in $3 \mathrm{sec}$ (FEV3)/FVC and the fraction of air not expired in the first $3 \mathrm{sec}$ (1-FEV3/FVC) are significantly correlated with gas trapping and lung hyperinflation (9). In addition, FEV1/FEV6 and FEV3/FEV6 are more sensitive than FEV1/FVC in the detection of early airflow limitation (10). Furthermore, the ratio of FVC to slow vital capacity may be an alternative marker for small airway collapse (11).

Plethysmography. Plethysmography is a method of lung volume examination that cannot be directly measured by spirometry. Residual air volume (RV) and RV/total lung volume (TLC) are commonly used to assess small airway function and provide accurate information about gas trapping and lung hyperinflation. It is now generally accepted that there is small airway dysfunction when RV is $>120 \%$ of the predicted value or RV/TLC is $>35 \%$ (12). Furthermore, studies have indicated that RV and RV/TLC are closely related to the degree of airway inflammation in small airways (13). The method has the advantages of a simple operation, better accuracy and precision, and high reproducibility; on the other hand, it is not specific to small airways and the equipment is expensive and occupies a large area, so it is currently not widely used.

Impulse oscillometry (IOS). IOS, based on the forced oscillation technique, is a simple and noninvasive novel method of lung function assessment. It has been indicated that it may be used to assess small airways. IOS parameters, such as total airway resistance (R5)-central airway resistance (R20), peripheral capacitance, resonant frequency (Fres) and reactance area (AX), are significantly correlated with FEF25-75\%, particularly Fres, which is more sensitive than FEF25-75\% in the diagnosis of small airway dysfunction (14). In patients with COPD and heavy smokers, Fres and R5-R20 are significantly correlated with the small airway area measured by intrabronchial optical coherence tomography (15). In addition, IOS may also be used to evaluate the severity of COPD, distinguish the site of obstruction, discriminate asthma from COPD and evaluate treatment effects (16). The novel approach has a number of advantages over other methods. One of the biggest advantages is that it is effort-independent (portable, user-operated capnograph devices and related methods), so it is thought to be of great potential.

Gas washout techniques. Gas washout techniques have been used in clinical practice for numerous years. Nitrogen is the most commonly used gas and in recent years, there has been increasing interest in helium washout systems.

Single breath nitrogen washout ( $S B N W$ ). SBNW uses the principle of conservation of energy. During the process, patients inhale $100 \%$ oxygen and then the nitrogen contained in the alveoli is gradually flushed and diluted, thus producing a curve representing the nitrogen concentration. According to the concentration of nitrogen in the exhaled air, the distribution of air in the lung is analysed. This may reflect the small airway functions of the closed volume $(\mathrm{CV})$, closing capacity $(\mathrm{CC})$ and third phase slope III (SIII). CV refers to the amount of remaining gas at the beginning of small airway closure. In healthy individuals, small airway closure occurs near the RV. CC refers to the total amount of $\mathrm{CV}$ and RV. A study indicated that the increase in CV and CC in patients with COPD was related to gas trapping caused by the premature closure of small airways. SIII refers to the slope of the third stage of the curve, which is normally a smooth curve with a slight upward trend and provides information on the ventilation distribution inhomogeneity (17). In patients with COPD, SIII exhibits obvious increases, which is related to lung ventilation inhomogeneity; furthermore, SIIII is correlated with FEV1\%, RV/TLC and diffusion capacity to carbon monoxide (DLCO) (18).

Multiple breath nitrogen washout (MBNW). MBNW represents an improvement over the SBNW test. The patient inhales $100 \%$ oxygen through a series of tidal breathing and then nitrogen is gradually washed out until the exhaled nitrogen concentration is nearly $1 / 40$ of the initial concentration. A measure frequently used to assess the overall gas mixing efficiency of the lungs is the lung clearance index (LCI). If ventilation distribution inhomogeneity increases, nitrogen removal is delayed and the LCI increases. A study has indicated that LCI may be used to evaluate early airway function in patients whose COPD diagnosis has not yet been confirmed with spirometry (19). Scond and sacin reflect the ventilation heterogeneity of the conducting airway and small airway in the acinar area, respectively. In smokers who have not yet met the diagnostic criteria for COPD, scond and sacin are able to detect small airway dysfunction prior to spirometer examination, particularly sacin (20). Furthermore, they may also be used to evaluate the severity of COPD (21). In addition, according to research, smokers with reduced pulmonary DLCO are more likely to develop COPD. Furthermore, in patients with mild to moderate COPD, DLCO is associated with small airway disease parameters, such as parametric response mapping (PRM) defined by CT scan, suggesting that the decrease in DLCO may indicate small airway dysfunction (22). The MBNW test requires a low level of patient cooperation, but it has not been widely used in clinical practice due to the requirement for standardized techniques.

Helium washout test. As a tracer gas, helium is less dense and is able to penetrate deep into the lungs for a certain period 
Table I. Advantages and disadvantages of methods for the assessment of small airway function.

\begin{tabular}{|c|c|c|c|}
\hline Method & Parameters & Advantages & Disadvantages \\
\hline Spirometry & $\begin{array}{l}\text { FEF50, FEF75\%, MMEF, } \\
\text { FEV3/FVC, 1-FEV3/FVC, } \\
\text { FEV1/FEV6, FEV3/FEV6, } \\
\text { FVC/SVC }\end{array}$ & $\begin{array}{l}\text { Noninvasive, easy to perform, } \\
\text { highly sensitive, promising }\end{array}$ & $\begin{array}{l}\text { Poor reproducibility and sensitivity, } \\
\text { not correlated with inflammation, } \\
\text { only reflects the overall function of } \\
\text { the lungs, further studies needed }\end{array}$ \\
\hline Plethysmography & $\mathrm{RV}, \mathrm{RV} / \mathrm{TLC}$ & $\begin{array}{l}\text { Accuracy and reproducibility, } \\
\text { correlates well with } \\
\text { inflammation }\end{array}$ & $\begin{array}{l}\text { Occupying large area, costly, not } \\
\text { widely available }\end{array}$ \\
\hline Impulse oscillometry & $\mathrm{X} 5, \mathrm{AX}$, Fres, R5-R20 & $\begin{array}{l}\text { Noninvasive, easy to } \\
\text { perform, highly sensitive, } \\
\text { effort-independent }^{\mathrm{a}}\end{array}$ & $\begin{array}{l}\text { Not widely available, further studies } \\
\text { needed }\end{array}$ \\
\hline $\begin{array}{l}\text { Single breath nitrogen } \\
\text { washout }\end{array}$ & $\mathrm{CV}, \mathrm{CC}, \mathrm{SIII}$ & $\begin{array}{l}\text { Sensitive to early change, good } \\
\text { reproducibility and sensitivity }\end{array}$ & $\begin{array}{l}\text { Difficult to perform, not widely } \\
\text { available }\end{array}$ \\
\hline $\begin{array}{l}\text { Multiple breath nitrogen } \\
\text { washout }\end{array}$ & LCI, Scond, Sacin, DLCO & $\begin{array}{l}\text { Good reproducibility and } \\
\text { sensitivity, effort-independent }\end{array}$ & $\begin{array}{l}\text { Difficult to perform, not widely } \\
\text { available }\end{array}$ \\
\hline Helium washout test & - & $\begin{array}{l}\text { Highly sensitive, good } \\
\text { repeatability and reliability }\end{array}$ & Further studies needed \\
\hline Exhaled nitric oxide & FeNO, CANO & Noninvasive, easy to perform & Further studies needed \\
\hline $\begin{array}{l}\text { High-resolution } \\
\text { computed tomography }\end{array}$ & MLDE/I, PRM, DPM & $\begin{array}{l}\text { Direct imaging of the lungs, } \\
\text { easy to perform }\end{array}$ & Costly, exposure to radiation \\
\hline $\begin{array}{l}\text { Hyperpolarized magnetic } \\
\text { resonance imaging }\end{array}$ & VDS, ADC & $\begin{array}{l}\text { Highly sensitive, no risk of } \\
\text { radiation exposure }\end{array}$ & Costly, technically demanding \\
\hline $\begin{array}{l}\text { Intrabronchial optical } \\
\text { coherence tomography }\end{array}$ & - & $\begin{array}{l}\text { Direct assessment of the airway } \\
\text { structure }\end{array}$ & Further studies required \\
\hline Serum markers & $\begin{array}{l}\text { Examples: Club cell } 16 \\
\text { protein, CXCL8, CX3CL1, } \\
\text { PAI-1 }\end{array}$ & Easy to obtain & Further studies required \\
\hline Induced sputum & Example: Pentosidine & Noninvasive & Further studies required \\
\hline $\begin{array}{l}\text { Bronchoalveolar } \\
\text { lavage }\end{array}$ & Example: MMPs & - & Invasive, further studies required \\
\hline Bronchoscopy biopsy & - & - & $\begin{array}{l}\text { Invasive, rarely used in everyday } \\
\text { practice }\end{array}$ \\
\hline
\end{tabular}

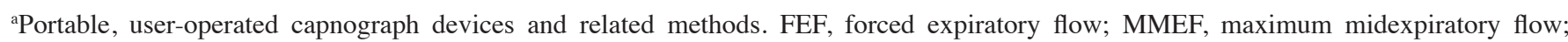
FEV, forced expiratory volume; FVC, forced vital capacity; SVC, slow vital capacity; RV, residual air volume; TLC, total lung volume; $\mathrm{X} 5$, peripheral capacitance; AX, reactance area; Fres, resonant frequency; R5, total airway resistance; R20, central airway resistance; $\mathrm{CV}$, closed volume; CC, closing capacity; SIII, third phase slope III; LCI, lung clearance index; DLCO, diffusion capacity to carbon monoxide; FeNO, fractional exhaled nitric oxide; CANO, alveolar concentration of exhaled nitric oxide; MLDE/I, mean lung density between expiratory and inspiratory; PRM, parametric response mapping; DPM, disease probability measure; VDS, ventilation defect score; ADC, apparent diffusion coefficient; CXCL8, C-X-C motif ligand 8; CX3CL1, CX3C chemokine ligand 1; PAI-1, plasminogen activator inhibitor-1; MMPs, matrix metalloproteinases.

of time, so it may also be used for gas washout techniques. According to research results, compared with the nitrogen washout test, the helium washout test is more sensitive to ventilation distribution inhomogeneity in the small airway (23). In addition, the sulfur hexafluoride and helium double-tracer gas washout test are able to detect early inflammatory changes in the small airways, similar to the nitrogen washout test, with better repeatability and reliability (24).

Exhaled nitric oxide (NO). NO, which is produced by airway cells and lung inflammatory cells, is able to reflect the level of inflammation in the lung, particularly eosinophilic airway inflammation. The measurement of the exhaled NO is flow rate-dependent. At low speed, $\mathrm{NO}$ mostly reflects the fractional exhaled NO (FENO) which comes from the central airway, whereas at high speed, it reflects the alveolar concentration of exhaled NO (CANO) which arises from the peripheral airway. FENO has been widely used in the clinical evaluation of central airway inflammation and therapeutic effects, although CANO is still under examination. According to certain studies, CANO increases in patients with COPD and increased CANO is related to changes in VC, RV/TLC, SIII and DLCO. After treatment, patients exhibited improvement in CANO and improved CANO correlated with other improved small airway 
indicators, suggesting that the CANO level is able to reflect peripheral airway dysfunction and may help predict clinical response to inhaled corticosteroids $(25,26)$. CANO measurement does not require any sophisticated equipment, but it is derived from computational extrapolation, rather than being directly quantified. Further research is required to determine its value.

Imaging technology. High-resolution computed tomography (HRCT) is a noninvasive method that provides anatomical details of the bronchial tree. The resolution threshold of HRCT is $1 \mathrm{~mm}$, whereas the thickness of the distal airway wall is $0.6-1 \mathrm{~mm}$. Therefore, it is still difficult to directly evaluate distal small airways. Currently, local gas trapping manifests as a mosaic attenuation area in HRCT caused by small airway lesions and is frequently used to indirectly evaluate small airways in clinical practice. However, the above performance is not specific and mainly depends on visual assessment and strong subjectivity. The ratio of mean lung density between expiratory and inspiratory CT (MLDE/I) is able to quantitatively evaluate the degree of gas trapping (27). However, as both emphysema and small airway disease in patients with COPD lead to areas of low attenuation and may independently predict the severity of COPD and airflow obstruction (28), it is important to identify whether gas retention is due to small airway disease or emphysema. It has been indicated that PRM and disease probability measure are able to identify the degree of functional small airway disease and emphysema and correlate well with FEV1, FEV1/FVC, RV/TLC and dyspnoea symptoms, suggesting that they may be used as novel indicators to identify small airway dysfunction (29). In recent years, investigators have focused efforts on improving the resolution of CT, and ultra-HRCT techniques have also developed rapidly and are able to accurately and directly evaluate peripheral airways with a diameter of $1-2 \mathrm{~mm}$ (30). Although CT is a useful, noninvasive tool for indirectly assessing small airway function, its use has been limited due to exposure of patients to radiation.

Conventional magnetic resonance imaging is rarely used for lung imaging due to technical limitations. Hyperpolarized magnetic resonance imaging is an increasing area of interest. Patients are required to inhale a polarized gas, such as helium, into the lungs, where it diffuses freely until it is blocked by the airway and alveolar walls. The signal distribution of hyperpolarized gas may provide ventilation images of pulmonary structures, reflecting local airflow and ventilation heterogeneity. ${ }^{3} \mathrm{He}$ is the most commonly used hyperpolarized gas. The ventilation defect percent and apparent diffusion coefficient (ADC) are commonly used in the assessment of small airway function. The ventilation deficiency score identifies small airway impairment in early smokers with normal lung function (31). With ${ }^{3} \mathrm{He}$ magnetic resonance imaging of healthy controls and patients with COPD, inhalation of hyperpolarized gas distributes reasonably homogeneously in healthy young adults, whereas patients with COPD have uneven signal distribution with patchy or wedge-shaped defects. Ventilation defect scale and pulmonary function test and emphysema detected by HRCT have a good correlation (32). Another commonly used index is the ADC, i.e., the diffusion motion of the hyperpolarized gas. Significant differences in ADC values between patients with COPD and healthy controls were detected and there were significant correlations with FEV1, RV, TLC, DLCO and PRM measured by CT (33). Indeed, ADC was more sensitive than MLDE/I in distinguishing patients with COPD from healthy controls and was more strongly correlated with DLCO (34). Further study also suggested that multiparametric response maps based on CT and ${ }^{3} \mathrm{He}$ MRI are able to detect emphysema and small airway dysfunction in former smokers with normal pulmonary function and CT manifestations (35). However, ${ }^{3} \mathrm{He}$ is a rare isotope whose source is limited to a certain extent. Investigators then focused their efforts on ${ }^{129} \mathrm{Xe}$ MRI. ${ }^{129} \mathrm{Xe}$ is not only abundant in source but also, compared with ${ }^{3} \mathrm{He}$ MRI, ${ }^{129} \mathrm{Xe}$ MRI is able to identify ventilation defects and ADC abnormity more sensitively (36). In conclusion, hyperpolarized magnetic resonance imaging has no risk of radiation exposure. However, this method has a high cost and technical requirements and has only been performed in a small number of research centres.

In recent years, nuclear medicine technology has developed rapidly and it has been demonstrated that ventilation/perfusion single photon emission computed tomography using Technegas technology-marked 99 mTc ultrafine carbon particles is able to detect early changes in small airways and grade the severity of small airway disease and lung function; furthermore, it is more sensitive than pulmonary and CT (37).

The diameter of traditional optical coherence tomography (OCT) exceeds the diameter of small airways and cannot be used to evaluate them. Endobronchial optical coherence tomography (EB-OCT) is a novel imaging method that is able to display the high-resolution cross-sectional structure of the airway wall. EB-OCT, which combines a superfine bronchoscope with novel navigation technology, is a new form of imaging. It is able to display the high-resolution cross-sectional structure of the airway wall and obtain more information on small airway walls, which is related to computed tomography and histological measurements (38).

Serum markers. In recent years, numerous serological indicators have been determined to reflect small airway obstruction, such as Club cell 16 protein, chemokines, particularly CXCL8 and CX3CL1 and plasminogen activator inhibitor-1. This method is more convenient, but further studies are needed (39-41).

Induced sputum. In recent years, certain studies have indicated that pentosidine in induced sputum exhibits obvious increases in COPD, which has a good correlation with mosaic attenuation of HRCT measurements and SIII, suggesting that it may be used as a potential biomarker of small airway obstruction (42).

Invasive operations. In addition, there are certain invasive methods, such as bronchoalveolar lavage and bronchoscopy biopsy, which may directly evaluate inflammation of the small airways. For instance, MMPs in bronchoalveolar lavage fluid may be used as a potential indicator of small airway function, particularly MMP8, which is significantly correlated with MLDE/I measured by CT (43). However, such methods are rarely used in routine clinical practice due to their invasive nature. 


\section{Treatment/management of COPD}

To prevent COPD, smoking cessation, as well as masking of non-cigarette forms of smoke exposure coming from cigars and biomass fuel, should be adopted (44). Routine management of COPD, albuterol, tiotropium and beclomethasone dipropionate (BDP), as well as spacers and peak flow meters, should be provided. If necessary, a nebulizer and pulse oximeter should also be added for support. The inhaled route for drug delivery and long-acting bronchodilators are recommended. Combined medication of long-acting muscarinic antagonist (LAMA)/long-acting beta agonist (LABA) is able to better improve lung function (improved FEV1 and transition dyspnoea index) and clinical status (reduced probability of short-term COPD worsening) for patients with COPD compared to those treated with LAMA or LABA monotherapy in a clinical randomised trial, and safety profiles were similar between treatments (45). Accordingly, LAMA/LABA dual therapy has been outlined in the GOLD 2021 guidelines for COPD due to its efficacy and safety (44). If, with either a history of $\geq 2$ moderate exacerbations or hospitalization(s) attributable to exacerbation, either serum eosinophilia (> 300 cells/ $\mu$ l) or coexisting with asthma is present, inhaled steroids are strongly recommended. In a randomized trial involving 10,355 patients with COPD, the rate of moderate or severe exacerbations in the triple-therapy group was lower than that in the dual therapy group $(0.91$ vs. $1.07, \mathrm{P}<0.001)$ and the annual rate of severe exacerbations resulting in hospitalization in the triple-therapy group was also lower than that in dual therapy group (0.13 vs. $0.19, \mathrm{P}<0.001)$ (46). Therefore, triple drug therapy (inhaled steroid/LAMA/LABA) has been recommended in the GOLD 2021 guidelines for COPD (44) and has become a standard scheme (47). In addition, hospitalized patients with COPD should supplement vitamin D if they are assessed for the severe vitamin D deficiency $(<10 \mathrm{ng} / \mathrm{ml}$ or $<25 \mathrm{nM}$ ) (48). In a randomised controlled trial, it was determined that vitamin D supplementation safely and substantially reduced the rate of moderate/severe COPD exacerbations in patients with baseline 25-hydroxyvitamin D levels $<25 \mathrm{nM}$ but not in those with higher levels (49). Another randomized, double-blinded, placebo-controlled clinical trial suggested that consumption of 50,000 IU vitamin D3, as a convenient supplementation to a daily diet, was able to increase quality of life in patients with COPD (50).

Apart from medical management, interventional procedures such as endobronchial valves are recommended according to appropriate indications such as hyperinflation, dyspnoea and health status (51). In consideration of the COVID-19 pandemic, patients with COPD should be tested to exclude COVID-19 and should wear surgical masks, maintain physical distance to avoid face-to-face contact, and then continue their medications as mentioned above (44).

The current pharmacological treatment of COPD is based on an inhalation preparation, whose drug particles are large, so most of them are deposited in the oropharynx and the atmospheric tract; only a small percentage of them reach the distal airways. Therefore, certain researchers hold the opinion that the symptoms of numerous patients have not been improved by the use of regular medication in clinical practice, which may be related to poor targeting of the distal airways (8). To date, the importance of targeted therapy for the small airways in clinical practice remains to be fully acknowledged and there is only a small number of studies specifically targeting the function and inflammation level of small airways in patients COPD prior to and after treatment, which leads to difficulties relating to how to achieve targeted therapy for small airways $(52,53)$. The administration of theophylline to patients with COPD with irreversible air-flow obstruction improved the small airway function manifested as ameliorating air trapping and airway resistance (52). The extrafine combination of BDP and formoterol $(\mathrm{BDP} / \mathrm{F})$ and the extrafine combination of extrafine $\mathrm{BDP} /$ formoterol fumarate (FF)/glycopyrronium bromide (GB) provide the possibility of targeted treatment of small airways. Studies have indicated that, compared with traditional preparations, the extrafine combination of $\mathrm{BDP} / \mathrm{F}$ is able to better improve the residual air volume and total lung volume and significantly improve dyspnoea symptoms (43). In addition, using functional respiratory imaging it was demonstrated that the extrafine combination of BDP/FF/GB has high lung deposition and peripheral airway deposition (54). In the future, the development of delivery devices and novel drug formulations aimed at small airway treatment are required.

\section{Conclusion}

Small airway diseases are widely present in COPD and have not received sufficient attention to date. Early recognition of small airway dysfunction and targeted treatment may improve clinical symptoms and delay disease progression. Whether there is a more convenient and accurate method to diagnose small airway dysfunction and how to better achieve targeted treatment of the small airway are questions to be addressed by future research.

\section{Acknowledgements}

Not applicable.

\section{Funding}

This work was supported by the Special Fund Project of the First Hospital of Shanxi Medical University (grant no. 136) and the Natural Science Fund of Shanxi Province (grant no. 201901D111186).

\section{Availability of data and materials}

Data sharing is not applicable to this article, as no datasets were generated or analyzed during the current study.

\section{Authors' contributions}

YL, XYL, HLW and LRY drafted the manuscript and table. MP edited, revised and approved the final version of the manuscript. Data authentication is not applicable. All authors read and approved the final version of the manuscript.

\section{Ethics approval and consent to participate}

Not applicable. 


\section{Patient consent for publication}

Not applicable.

\section{Competing interests}

The authors declare that they have no competing interests.

\section{References}

1. López-Campos JL, Tan W and Soriano JB: Global burden of COPD. Respirology 21: 14-23, 2016.

2. Crisafulli E, Pisi R, Aiello M, Vigna M, Tzani P, Torres A, Bertorelli G and Chetta A: Prevalence of small-airway dysfunction among COPD patients with different GOLD stages and its role in the impact of disease. Respiration 93: $32-41,2017$

3. Hogg JC, Pare PD and Hackett TL: The contribution of small airway obstruction to the pathogenesis of chronic obstructive pulmonary disease. Physiol Rev 97: 529-552, 2017.

4. Barnes PJ: Inflammatory mechanisms in patients with chronic obstructive pulmonary disease. J Allergy Clin Immunol 138 : $16-27,2016$.

5. Higham A, Quinn AM, Cancado JED and Singh D: The pathology of small airways disease in COPD: Historical aspects and future directions. Respir Res 20: 49, 2019.

6. Day K, Ostridge K, Conway J, Cellura D, Watson A, Spalluto CM, Staples KJ, Thompson B and Wilkinson T: Interrelationships among small airways dysfunction, neutrophilic inflammation, and exacerbation frequency in COPD. Chest 159: 1391-1399, 2021.

7. Graham BL, Steenbruggen I, Miller MR, Barjaktarevic IZ, Cooper BG, Hall GL, Hallstrand TS, Kaminsky DA, McCarthy K, McCormack MC, et al: Standardization of spirometry 2019 update. An official american thoracic society and european respiratory society technical statement. Am J Respir Crit Care Med 200: e70-e88, 2019.

8. Morris ZQ, Coz A and Starosta D: An isolated reduction of the FEV3/FVC ratio is an indicator of mild lung injury. Chest 144: $1117-1123,2013$

9. Borekci S, Demir T, Gorek Dilektasli A, Uygun M and Yildirim N: A simple measure to assess hyperinflation and air trapping: 1-Forced expiratory volume in three second/forced vital capacity. Balkan Med J 34: 113-118, 2017.

10. Dilektasli AG, Porszasz J, Casaburi R, Stringer WW, Bhatt SP, Pak Y, Rossiter HB, Washko G, Castaldi PJ, Estepar RSJ, et al: A novel spirometric measure identifies mild COPD unidentified by standard criteria. Chest 150: 1080-1090, 2016.

11. Saint-Pierre M, Ladha J, Berton DC, Reimao G, Castelli G, Marillier M, Bernard AC, O'Donnell DE and Neder JA: Is the slow vital capacity clinically useful to uncover airflow limitation in subjects with preserved FEV1/FVC ratio? Chest 156: 497-506, 2019.

12. Wu J, Lu AD, Zhang LP, Zuo YX and Jia YP: Study of clinical outcome and prognosis in pediatric core binding factor-acute myeloid leukemia. Zhonghua Xue Ye Xue Za Zhi 40: 52-57, 2019 (In Chinese).

13. Li K, Gao Y, Pan Z, Jia X, Yan Y, Min X, Huang K and Jiang T: Influence of emphysema and air trapping heterogeneity on pulmonary function in patients with COPD. Int J Chron Obstruct Pulmon Dis 14: 2863-2872, 2019.

14. Chiu HY, Hsiao YH, Su KC, Lee YC, Ko HK and Perng DW: Small airway dysfunction by impulse oscillometry in symptomatic patients with preserved pulmonary function. J Allergy Clin Immunol Practe 8: 229-235.e3, 2020.

15. Su ZQ, Guan WJ, Li SY, Ding M, Chen Y, Jiang M, Chen XB, Zhong CH, Tang CL and Zhong NS: Significances of spirometry and impulse oscillometry for detecting small airway disorders assessed with endobronchial optical coherence tomography in COPD. Int J Chron Obstruct Pulmon Dis 13: 3031-3044, 2018.

16. Desai U and Joshi JM: Impulse oscillometry. Adv Respir Med 87: 235-238, 2019

17. Kanazawa $\mathrm{H}$, Tochino $\mathrm{Y}$, Kyoh S, Ichimaru $\mathrm{Y}$, Asai $\mathrm{K}$ and Hirata K: Potential roles of pentosidine in age-related and disease-related impairment of pulmonary functions in patients with asthma. J Allergy Clin Immunol 127: 899-904, 2011.
18. Boeck L, Gensmer A, Nyilas S, Stieltjes B, Re TJ, Tamm M, Latzin P and Stolz D: Single-breath washout tests to assess small airway disease in COPD. Chest 150: 1091-1100, 2016.

19. Bell AS, Lawrence PJ, Singh D and Horsley A: Feasibility and challenges of using multiple breath washout in COPD. Int J Chron Obstruct Pulmon Dis 13: 2113-2119, 2018.

20. Jetmalani K, Thamrin C, Farah CS, Bertolin A, Chapman DG, Berend N, Salome CM and King GG: Peripheral airway dysfunction and relationship with symptoms in smokers with preserved spirometry. Respirology 23: 512-518, 2018.

21. Liu B, Zhou Q and He B: The application of multiple breath nitrogen washout in chronic obstructive pulmonary disease. Zhonghua Jie He He Hu Xi Za Zhi 38: 492-496, 2015 (In Chinese).

22. Criner RN, Hatt CR, Galban CJ, Kazerooni EA, Lynch DA, McCormack MC, Casaburi R, MacIntyre NR, Make BJ, Martinez FJ, et al: Relationship between diffusion capacity and small airway abnormality in COPDGene. Respir Res 20: 269, 2019.

23. Wang JY, Suddards ME, Mellor CJ and Owers-Bradley JR: Lung function measurement with multiple-breath-helium washout system. Med Eng Phys 35: 457-469, 2013.

24. Port J, Tao Z, Junger A, Joppek C, Tempel P, Husemann K, Singer F, Latzin P, Yammine S, Nagel JH and Kohlhäufl M: A simple method to reconstruct the molar mass signal of respiratory gas to assess small airways with a double-tracer gas single-breath washout. Med Biol Eng Comput 55: 1975-1987, 2017.

25. Hirano T, Matsunaga K, Sugiura H, Minakata Y, Koarai A, Akamatsu K, Ichikawa T, Furukawa K and Ichinose M: Relationship between alveolar nitric oxide concentration in exhaled air and small airway function in COPD. J Breath Res 7: 046002, 2013.

26. Santus P, Radovanovic D, Mascetti S, Pauletti A, Valenti V, Mantero M, Papi A and Contoli M: Effects of bronchodilation on biomarkers of peripheral airway inflammation in COPD. Pharmacoll Res 133: 160-169, 2018.

27. Hersh CP, Washko GR, Estépar RS, Lutz S, Friedman PJ, Han MK, Hokanson JE, Judy PF, Lynch DA, Make BJ, et al: Paired inspiratory-expiratory chest CT scans to assess for small airways disease in COPD. Respir Res 14: 42, 2013.

28. Timmins SC, Diba C, Farrow CE, Schoeffel RE, Berend N, Salome CM and King GG: The relationship between airflow obstruction, emphysema extent, and small airways function in COPD. Chest 142: 312-319, 2012.

29. Vasilescu DM, Martinez FJ, Marchetti N, Galbán CJ, Hatt C, Meldrum CA, Dass C, Tanabe N, Reddy RM, Lagstein A, et al: Noninvasive imaging biomarker identifies small airway damage in severe chronic obstructive pulmonary disease. Am J Respir Crit Care Med 200: 575-581, 2019.

30. Tanabe N, Shima H, Sato S, Oguma T, Kubo T, Kozawa S, Koizumi K, Sato A, Togashi K and Hirai T: Direct evaluation of peripheral airways using ultra-high-resolution CT in chronic obstructive pulmonary disease. Eur J Radiol 120: 108687, 2019.

31. Pike D, Kirby M, Guo F, McCormack DG and Parraga G: Ventilation heterogeneity in ex-smokers without airflow limitation. Acad Radiol 22: 1068-1078, 2015.

32. Stavngaard T, Sogaard LV, Mortensen J, Hanson LG, Schmiedeskamp J, Berthelsen AK and Dirksen A: Hyperpolarized 3He MRI and $81 \mathrm{mKr}$ SPECT in chronic obstructive pulmonary disease. Eur J Nucl Med Mol Imaging 32: 448-457, 2005.

33. Capaldi DP, Zha N, Guo F, Pike D, McCormack DG, Kirby M and Parraga G: Pulmonary imaging biomarkers of gas trapping and emphysema in COPD: (3)He MR imaging and CT parametric response maps. Radiology 279: 597-608, 2016.

34. van Beek EJ, Dahmen AM, Stavngaard T, Gast KK, Heussel CP, Krummenauer F, Schmiedeskamp J, Wild JM, Søgaard LV, Morbach AE, et al: Hyperpolarised 3He MRI versus HRCT in COPD and normal volunteers: PHIL trial. Eur Respir J 34: 1311-1321, 2009.

35. MacNeil JL, Capaldi DPI, Westcott AR, Eddy RL, Barker AL, McCormack DG, Kirby M and Parraga G: Pulmonary imaging phenotypes of chronic obstructive pulmonary disease using multiparametric response maps. Radiology 295: 227-236, 2020.

36. Kirby M, Svenningsen S, Owrangi A, Wheatley A, Farag A, Ouriadov A, Santyr GE, Etemad-Rezai R, Coxson HO, McCormack DG and Parraga G: Hyperpolarized 3He and 129Xe MR imaging in healthy volunteers and patients with chronic obstructive pulmonary disease. Radiology 265: 600-610, 2012.

37. Yokoe K, Satoh K, Yamamoto Y, Nishiyama Y, Asakura H, Haba R and Ohkawa M: Usefulness of $99 \mathrm{mTc}$-Technegas and 133Xe dynamic SPECT in ventilatory impairment. Nucl Medi Commun 27: 887-892, 2006. 
38. Chen Y, Ding M, Guan WJ, Wang W, Luo WZ, Zhong $\mathrm{CH}$, Jiang M, Jiang JH, Gu YY, Li SY and Zhong NS: Validation of human small airway measurements using endobronchial optical coherence tomography. Respir Med 109: 1446-1453, 2015.

39. Braido F, Riccio AM, Guerra L, Gamalero C, Zolezzi A Tarantini F, De Giovanni B, Folli C, Descalzi D and Canonica GW: Clara cell 16 protein in COPD sputum: A marker of small airways damage? Respir Med 101: 2119-2124, 2007.

40. Hao W, Li M,Pang Y, Du W and Huang X: Increased chemokines levels in patients with chronic obstructive pulmonary disease: Correlation with quantitative computed tomography metrics. Br J Radiol 94: 20201030, 2021.

41. Wang H, Yang T, Li D, Wu Y, Zhang X, Pang C, Zhang J, Ying B, Wang $T$ and Wen F: Elevated circulating PAI-1 levels are related to lung function decline, systemic inflammation, and small airway obstruction in chronic obstructive pulmonary disease. Int J Chron Obstruct Pulmon Dis 11: 2369-2376, 2016.

42. Kawamoto $\mathrm{T}$, Kanazawa $\mathrm{H}$, Tochino $\mathrm{Y}$ and Kawaguchi $\mathrm{T}$ : Evaluation of the severity of small airways obstruction and alveolar destruction in chronic obstructive pulmonary disease. Respir Med 141: 159-164, 2018.

43. Ostridge K, Williams N, Kim V, Bennett M, Harden S, Welch L, Bourne S, Coombs NA, Elkington PT, Staples KJ and Wilkinson TM: Relationship between pulmonary matrix metalloproteinases and quantitative CT markers of small airways disease and emphysema in COPD. Thorax 71: 126-132, 2016.

44. Gupta N, Malhotra N and Ish P: GOLD 2021 guidelines for COPD-what's new and why. Adv Respir Med 89: 344-346, 2021.

45. Maltais F, Bjermer L, Kerwin EM, Jones PW, Watkins ML, Tombs L, Naya IP, Boucot IH, Lipson DA, Compton C, et al: Efficacy of umeclidinium/vilanterol versus umeclidinium and salmeterol monotherapies in symptomatic patients with COPD not receiving inhaled corticosteroids: The EMAX randomised trial. Respir Res 20: 238, 2019.

46. Lipson DA, Barnhart F, Brealey N, Brooks J, Criner GJ, Day NC, Dransfield MT, Halpin DMG, Han MK, Jones CE, et al: Once-daily single-inhaler triple versus dual therapy in patients with COPD. N Engl J Med 378: 1671-1680, 2018.
47. Rabe KF, Martinez FJ, Ferguson GT, Wang C, Singh D, Wedzicha JA, Trivedi R, St Rose E, Ballal S, McLaren J, et al: Triple inhaled therapy at two glucocorticoid doses in Moderate-to-Very-Severe COPD. N Engl J Med 383: 35-48, 2020.

48. Gupta N, Agrawal S, Chakrabarti S and Ish P: COPD 2020 Guidelines-what is new and why? Adv Respir Med 88: 38-40, 2020.

49. Jolliffe DA, Greenberg L, Hooper RL, Mathyssen C, Rafiq R, de Jongh RT, Camargo CA, Griffiths CJ, Janssens W and Martineau AR: Vitamin D to prevent exacerbations of COPD: Systematic review and meta-analysis of individual participant data from randomised controlled trials. Thorax 74: 337-345, 2019.

50. Alavi Foumani A, Mehrdad M, Jafarinezhad A, Nokani K and Jafari A: Impact of vitamin D on spirometry findings and quality of life in patients with chronic obstructive pulmonary disease: A randomized, double-blinded, placebo-controlled clinical trial. Int J Chron Obstruct Pulmon Dis 14: 1495-1501, 2019.

51. Criner GJ, Delage A, Voelker K, Hogarth DK, Majid A, Zgoda M, Lazarus DR, Casal R, Benzaquen SB, Holladay RC, et al: Improving lung function in severe heterogenous emphysema with the spiration valve system (EMPROVE). A multicenter, open-label randomized controlled clinical trial. Am J Respir Crit Care Med 200: 1354-1362, 2019.

52. Santus P, Radovanovic D, Pecchiari M, Ferrando M, Tursi F, Patella V and Braido F: The Relevance of targeting treatment to small airways in asthma and COPD. Respir Care 65: 1392-1412, 2020.

53. Lavorini F, Pedersen S and Usmani OS: Dilemmas, confusion, and misconceptions related to small airways directed therapy. Chest 151: 1345-1355, 2017.

54. Usmani OS, Mignot B, Kendall I, Maria R, Cocconi D, Georges G and Scichilone N: Predicting lung deposition of extrafine inhaled corticosteroid-containing fixed combinations in patients with chronic obstructive pulmonary disease using functional respiratory imaging: An in silico study. J Aerosol Med Pulm Drug Deliv 34: 204-211, 2020. 